\title{
Un jardín para la Damatemática
}

\section{La teoría de grafos se materializa en la UMH}

- Lorena Santos

$\mathbf{E}$

n la antigua Königsberg prusiana, Kaliningrado (Rusia), había siete viaductos que cruzaban el río Pregel y dividían el terreno en cuatro regiones distintas solo unidas por estos puentes: el del herrero, el conector, el verde, el del mercado, el de madera, el alto y el de la miel. En el siglo XVIII se formuló el reto de encontrar un recorrido para cruzar a pie toda la ciudad, de forma que solo se pasara una vez por cada uno de los puentes para volver al inicio. El matemático Leonhard Euler demostró en 1736 que no se puede trazar una ruta sin repetir el paso por alguno, sin embargo, esta teoría ha dado lugar al concepto de grafo que es un tipo de estructura de datos utilizada en ciencias de la computación y matemática discreta.

Con la Teoría de Grafos como herramienta para generar un entorno agradable y con el álgebra para crear una escultura, un grupo de profesores del Centro de Investigación Operativa $(\mathrm{ClO})$ y del Departamento de Fí- sica y Arquitectura de Computadores, con inquietudes de divulgar las matemáticas, consideraron la importancia de crear un jardín que recrease la propia ciudad de Königsberg. Mari Carmen Perea, María Victoria Herranz, Joaquín Sánchez Soriano, Vicente Galiano y el artista Cayetano Ramírez recibieron una subvención concedida en 2007 por la Fundación Española para la Ciencia y la Tecnología del Ministerio de Ciencia y Tecnología (FECYT) para la construcción de la Damatemática y la del propio jardín. En una de sus islas, este entorno de la UMH contiene la escultura, de forma cúbica, construida con piedra calcárea cristalizada de dimensiones 300 $\mathrm{cm} \times 257 \mathrm{~cm} \times 127 \mathrm{~cm}$ y un peso aproximado de II.000 kilogramos, que sigue el patrón de un polinomio de grado tres, mediante la intersección con un cilindro, como explica Herranz: "Es una superficie con un punto de discontinuidad doble A2, cuyos planos tangentes en ese punto cortan a la superficie en tres rectas". Es curioso que, a pesar de que esta no era la intención, el resultado se

\author{
La escultura es \\ la superficie cúbica \\ hecha a mano más \\ grande del mundo
}

asemeje a una versión abstracta de la Dama de Elche, motivo por el que se le empezó a llamar Damatemática. Además, se trata de la superficie cúbica realizada a mano más grande del mundo. Cayetano Ramírez afirma que la mayor dificultad que tuvo fue trazar las líneas rectas. El escultor define la conexión entre el arte y las matemáticas como un antagonismo conjuntado cuyo resultado es la posición: "La naturaleza contiene matemáticas a diestro y siniestro y a través de éstas se pueden obtener formas inimaginables".

Dentro del proyecto de la FECYT también se realizaron unos pósteres de divulgación sobre las diferentes áreas matemáticas en las que trabaja el $\mathrm{ClO}$ y se solicitaron unas 


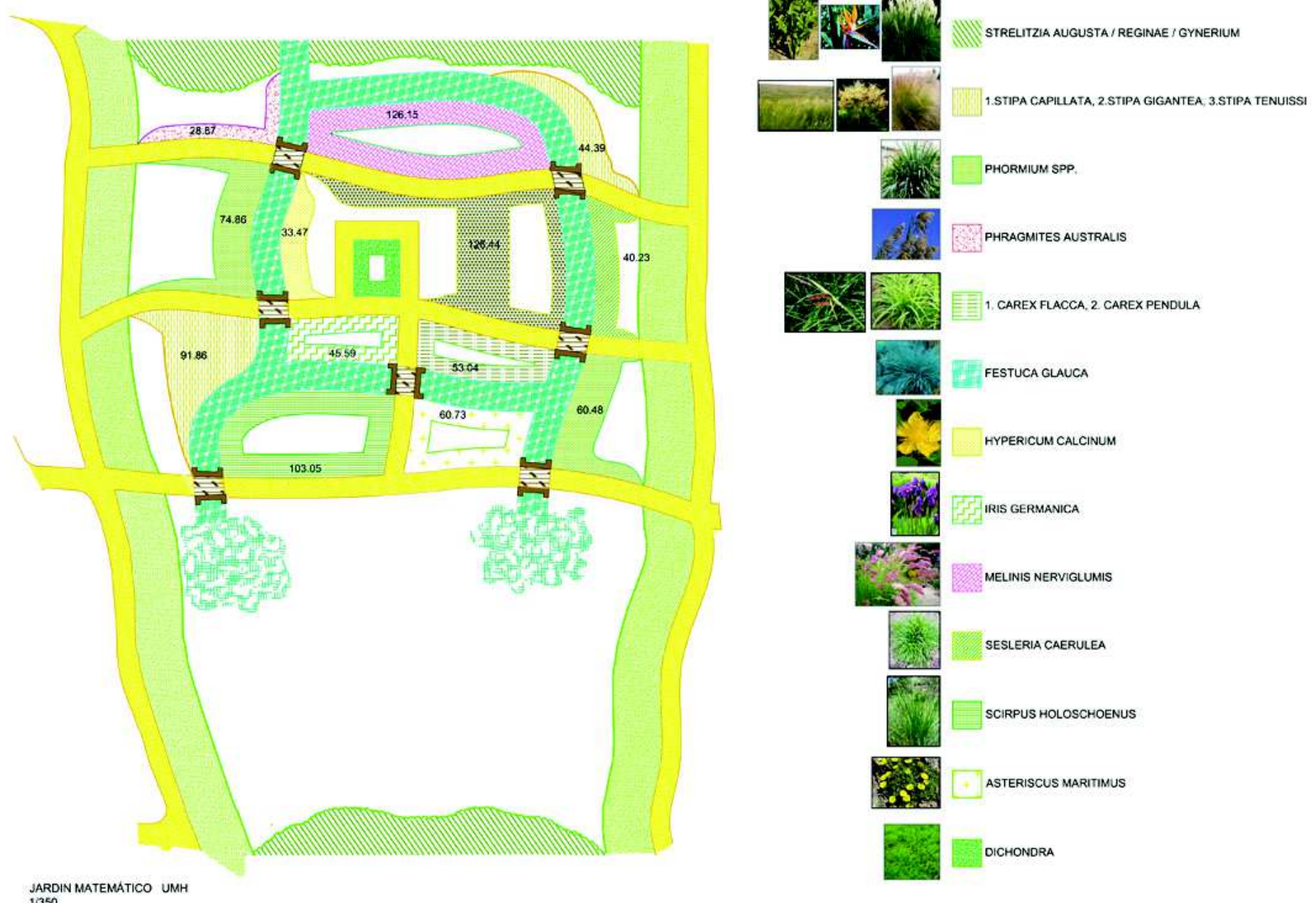

acciones que, aunque no llegaron a materializarse quedan pendientes para próximas subvenciones de proyectos divulgativos. "En el jardín, que tendría como figura principal la escultura, se pretendía representar los cuatro elementos: agua, tierra, fuego y aire, con flores de diversos colores. También se deseaba incluir juegos como el ajedrez o el tangram, que guardan relación con las ciencias exactas”, explica Perea. Además, el diseño incluye un reloj de sol analemático, en el que la persona se sitúa en una marca -que varía según el mes del año- y proyecta su propia sombra para indicar la hora. El plan también contemplaba una web con una virtualización del edificio del $\mathrm{ClO}$ convertido en un museo. De esta forma, cada uno de los despachos virtuales albergaría biografías, investigaciones de los últimos tiempos y curiosidades matemáticas. Aunque el presupuesto no ha sido suficiente para terminar el jardín, el grupo sigue con la intención de retomar el proyecto y crear una pequeña Königsberg en la UMH.

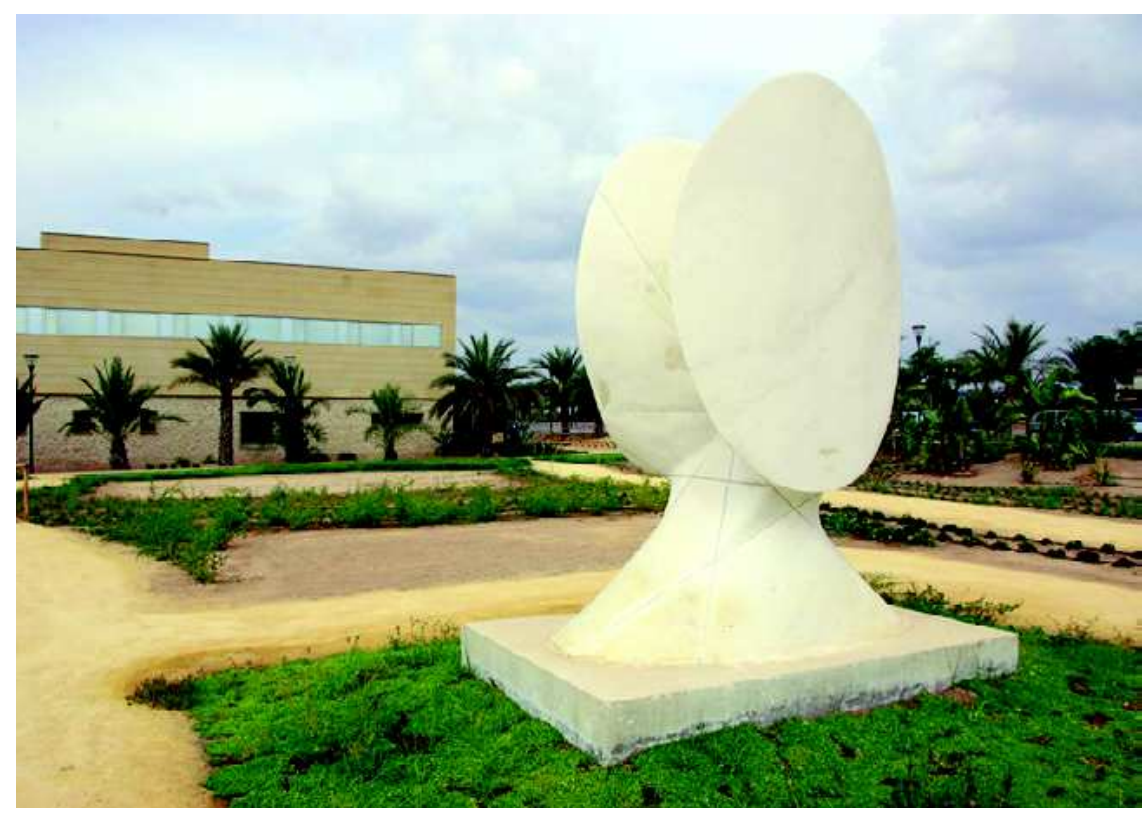

La ecuación del espacio proyectivo ha sido obtenida del artículo Cayley, A Memoir on Cubic Surfaces, Phil. Trans. Royal Soc., CLIX, pp. 231-326, 1869.

La ecuación matemática de esta figura es: $w(x+y+z)^{2}+x y z=0$ 